\title{
Human Intestinal Mucin in Cystic Fibrosis
}

\author{
A. WESLEY, J. FORSTNER, R. QURESHI, M. MANTLE, AND G. FORSTNER ${ }^{(37)}$ \\ Research Institute, Departments of Paediatrics and Biochemistry, Hospital for Sick Children, and the University of \\ Toronto, Toronto, Canada
}

\begin{abstract}
Summary
Human intestinal mucins from six subjects with Cystic Fibrosis (CF) and eight subjects without CF were prepared from tissue obtained at surgery (one case) and postmortem. Subjects were not age-matched, but the nonCF mucin was obtained from subjects with ages which bracketed those of the CF subjects. Cesium chloride analytical gradient ultracentrifugation showed that $\mathrm{CF}$ mucins were generally denser than nonCF mucins. Sedimentation coefficients were also higher in the $C F$ samples. $C F$ mucins were enriched in fucose, galactose, $\mathrm{N}$-acetylglucosamine and total carbohydrate per mg protein and per oligosaccharide chain (mole/ mole GalNAc). Fucose/sialic acid molar ratios were significantly higher in CF mucins, and the average oligosaccharide chain length was approximately three residues greater in $\mathrm{CF}$ as compared with nonCF mucins. There was no difference in amino acid profiles or the number of side chains per molecule. The mean sulfate content was higher in the CF mucins but not to a level of significance; however, in the eight mucins, sulfate content correlated positively with total carbohydrate, $\mathrm{N}$-acetylglucosamine and galactose, and therefore increased with oligosaccharide chain length. CF intestinal mucin was therefore denser and more highly glycosylated than nonCF musin and probably contained more sulfate. The increase in glycosylation resulted from a rise in fucose, galactose, and $\mathrm{N}$-acetylglucosamine without a concomitant rise in sialic acid.
\end{abstract}

\section{Speculation}

Hyperglycosylation with an associated increase in average chain length of carbohydrate side chains ought to increase the equivalent hydrodynamic volume of the mucin molecule and so result in enhanced viscosity and gelling. These features may contribute to the hyperviscosity often noted in mucus-rich secretions in CF and could enhance mucus plugging of small ducts. Increased mucin carbohydrate could represent one of the fundamental abnormalities contributing to the pathology of this disease.

Farber (10) first raised the possibility of a mucus abnormality in Cystic Fibrosis in 1945 because of the presence at autopsy of distension and obstruction of many mucus-producing glands.

Two abnormalities of the composition of mucus glycoproteins have been reported previously, one related to increased fucose, and the other to increased sulfate. Dische et al. (9) in 1959 found an increase in the fucose content of a glycoprotein fraction isolated from duodenal secretion with a consequent high ratio of fucose to sialic acid. Further studies by Roelfs et al. (31) on mucus from rectal washings, and Johansen (19) on sputum also indicated elevated fucose levels in patients with cystic fibrosis, although Potter et al. (29) found a lower fucose level in sputum of patients with cystic fibrosis than controls. A recent study by Clamp and Gough (7) on the mucus glycoproteins of meconium, found that the pooled CF sample (blood group A) had a much higher content of fucose than a normal blood group A specimen. Guha et al. (15) have reported that salivary glycoproteins of CF patients incorporated significantly more fucose than the same glycoproteins from controls.
A higher mucus sulfate content in CF was first suggested by histochemical studies $(21,24)$ where a larger proportion of mucussecreting cells stained for sulfomucins. A recent histochemical study (27) using scanning densitometry showed a quantitative increase in sulfomucins in the small intestine of infants with $\mathrm{CF}$. Biochemical studies of bronchial mucins $(4,22)$ have shown that a higher proportion of the mucus glycoprotein from subjects with cystic fibrosis is sulfated; however, Lamb and Reid (20) have demonstrated age-related changes in sulfation of bronchial mucins, and Lamblin et al. (22) concluded that the apparent increase in sulfation in the CF mucus glycoprotein from sputum could be related to the age of the subjects studied. Lamb and Reid (21) also found increased sulfomucins in bronchiectasis unrelated to cystic fibrosis, indicating that increased sulfation in mucus glycoprotein from the lung could be the result and not the cause of the pathologic process.

In this study we report the results of analysis of small intestinal mucus glycoproteins from six subjects with cystic fibrosis and eight control subjects. The previous biochemical studies on the mucus glycoproteins of sputum have suffered because of the small numbers of samples examined and the difficulty in obtaining normal control specimens. We have chosen to study the mucus glycoproteins of the small intestine, because in this organ the results are unlikely to be due to the secondary effects of infection or bronchial obstruction which have added to the difficulty in interpretation of results from sputum.

\section{MATERIALS AND METHODS}

Preparation of human intestinal mucin. Human small intestine was obtained from subjects with cystic fibrosis and control subjects within $12 \mathrm{~h}$ postmortem (mostly within $8 \mathrm{~h}$ ). Goblet cell mucin from 10 samples was isolated as previously described (18) by applying the postmicrosomal supernatant solutions to Sepharose $4 \mathrm{~B}$ columns $(90 \times 2.5 \mathrm{~cm}, 138 \times 4 \mathrm{~cm})$. The mucin was eluted in the void volume. Further purification of the pooled mucin was performed by nuclease enzyme digestion and Sepharose $2 \mathrm{~B}$ column chromatography $(3.5 \times 99 \mathrm{~cm})$. Nucleic acid content was estimated from the ratio of optical densities at 280 and $260 \mathrm{~nm}$ (23). Five $\mu$ of RNAse (bovine pancreas, P.L. Biochemicals, Milwaukee, WI) and $5 \mu$ of DNAse (bovine pancreas, P.L. Biochemicals) were used for each $\mu \mathrm{g}$ of nucleic acid and digestions were performed at room temperature for $25 \mathrm{~h}$ in $0.1 \mathrm{M} \mathrm{K}_{2} \mathrm{HPO}_{4}$ $\mathrm{KH}_{2} \mathrm{PO}_{4}$ buffer, $\mathrm{pH} 7.4$, containing $0.01 \mathrm{M} \mathrm{MgCl}$ and $0.02 \% \mathrm{Na}$ azide. After digestion, the samples were centrifuged at $10,000 \mathrm{rpm}$ for $10 \mathrm{~min}$ and the supernatant applied to a Sepharose 2B column. The void volume hexose peak [hexose assayed by the Anthrone method (34)] was pooled, dialysed, concentrated by lyophilisation and resuspended in ice cold distilled water. Subsequent analyses were performed on this material. Purity was monitored by carbohydrate analysis and polyacrylamide gel electrophoresis. The mucins were free of uronic acid with trace amounts of mannose (see "Results"). Polyacrylamide gel electrophoresis revealed zero to trace amounts of low molecular weight protein contaminants as detected by the sensitive silver stain of Oakley et al. (28).

Analytical density gradient ultracentrifugation in $\mathrm{CsCl}$. Mucin samples were stained with periodic acid/schiff reagent (17). Sam- 
ples were diluted with phosphate saline buffer ( $33 \mathrm{mM} \mathrm{NaCl}, 16.7$ $\mathrm{mM} \mathrm{Na} \mathrm{HPO}_{4}, \mathrm{pH} 6.8$ ) to give optical density readings at $555 \mathrm{~nm}$ of $0.3-0.5$. $\mathrm{CsCl}$ was added to mucin samples to give $42 \%$ of w/w $\mathrm{CsCl}$ solution. The concentration of mucin protein varied from $17-60 \mu \mathrm{g} / \mathrm{ml} \mathrm{CsCl}$ solution. Density of the final solution was checked by refractive index measurements (5).

Centrifugation was performed at $25^{\circ} \mathrm{C}$ at $44,000 \mathrm{rpm}$ for $24 \mathrm{~h}$ in 12-mm double sector cells in an An-H Titanium rotor in a Beckman model E centrifuge.

Buoyant densities were calculated from $555 \mathrm{~nm}$ tracings by using standard formulae (5).

Band ultracentrifugation. Sedimentation analyses were carried out by band ultracentrifugation as previously described (17) in an An-K aluminium rotor using $30 \mathrm{~mm}$ band-forming cells. Sedimentation coefficients $\left(\mathrm{S}^{\circ}{ }_{20, \mathrm{~W}}\right)$ could be calculated in single runs from measurements of the light absorption profiles at $555 \mathrm{~nm}$. The final concentration of mucin in each run varied between $2-10 \mu \mathrm{g}$ mucin protein $/ \mathrm{ml}$.

Amino acid analyses. These were performed on hydrolysates (5.5 $\mathrm{M} \mathrm{HCl}, 16$ or $22 \mathrm{~h}, 110^{\circ} \mathrm{C}$ in vacuo) on a Durrum amino acid analyser.

Carbohydrate analyses. Carbohydrates were determined by gas liquid chromatography of the trifluoroacetate derivatives of the $\mathrm{O}$-methyl glycosides after hydrolysis with $0.5 \mathrm{M}$ methanolic $\mathrm{HCl}$ at $80^{\circ} \mathrm{C}$ for $20 \mathrm{~h}$, using inositol as the internal standard (36). Five $\mu \mathrm{l}$ aliquots were injected into the column $\left(3 \% \mathrm{OV}-2106^{\prime} \times 1 / 4\right.$ " OD) of a Varian integrator CDS III. $N$-acetylgalactosamine and $\mathrm{N}$-acetylglucosamine were also measured on a Durrum amino acid analyser after hydrolysis of samples in $4 \mathrm{~N} \mathrm{HCl}$ at $100^{\circ} \mathrm{C}$ for $7 \mathrm{~h}$.

Blood group reactivity. Blood group activity in each sample was tested by standard haemagglutination inhibition techniques using Anti A, Anti B, (Hyland Div., Travenol Labs, Glendale, CA), Anti Le antiserum (Ortho Diagnostic Systems, Rantan, NJ) and Anti $\mathrm{H}$ lectin Ulex Europeus (Hyland Div., Travenol Labs, Glendale, CA).

Sulfate assay. Sulfate was determined by the method of Mende and Whitney (25), by precipitation of $\left[{ }^{133} \mathrm{Ba}\right]-\mathrm{SO}_{4}$ on thin layer plates spotted with mucin samples which had been hydrolysed in $25 \%$ formic acid at $100^{\circ} \mathrm{C}$ for $24 \mathrm{~h}$. The washing procedure was modified slightly by performing descending (rather than ascending) chromatography which was allowed to run over $18-36 \mathrm{~h}$, after which the plates were dried and strips cut and counted in a Beckman Gamma Counter. Standards of $\mathrm{K}_{2} \mathrm{SO}_{4}$ were prepared to contain from $0.5-2 \mu \mathrm{g} \mathrm{SO}_{4}$ and these were plated together with a blank of the $25 \%$ formic acid hydrolysis medium. Two plates could be run at one time and samples and standards were plated in duplicate, one on each plate.

Four mucin samples (two CF and two control) were isolated and purified somewhat differently in initial work in our laboratory. Goblet cell mucin in those samples consisted of the supernatant of the void volume peak from a Sepharose 4B column after centrifugation at $30,000 \mathrm{~g}$ for $30 \mathrm{~min}$. Monosaccharides in these preparations were analysed by the gas liquid chromatography method of Clamp et al. (6). Because analyses were expressed per $\mathrm{mg}$ dry weight, they are not included in carbohydrate per $\mathrm{mg}$ of protein results, but are included wherever possible in the remainder of the data. Results were analysed for 10 and/or 14 samples, and in no instance did the inclusion of the additional four cases alter the conclusions or affect their validity.

\section{RESULTS}

The subjects from whom specimens of small intestine were obtained are listed in Table 1 . All samples were obtained within $12 \mathrm{~h}$ postmortem except one, which was obtained at operation for blind loop syndrome when a section of dilated jejunum was removed. The mucosa of this specimen was histologically normal.

The age of the eight controls ranged from 1 day to 90 years, whereas that of the six subjects was from 9-23 years. The diagnoses of the control subjects are listed. The blood groups and secretor status show that there was an approximately equal incidence of nonsecretor mucin specimens in each group. The principal difference between the groups was the presence of three A determinants in the control secretor mucins, as compared with none in the CF mucins.

Amino acid analysis (Table 2) of 14 mucin samples showed a profile typical of mucins, with high threonine, serine, and proline ( $>45 \%$ of total). No difference was seen between cystic fibrosis and control samples. Half cysteine residues were not quantitated.

Analytical density gradient ultracentrifugation was performed in six control and four CF subjects. The buoyant density of glycoproteins tends to be related directly to their carbohydrate content (3) and therefore this technique provides a rough indication of relative degrees of glycosylation. In the four CF samples, virtually all of the mucin had a buoyant density greater than 1.44 $\mathrm{g} / \mathrm{ml}$, generally with a major peak greater than 1.46 . Only one of the nonCF mucins had a similar pattern; the remainder had much more heterogeneous density patterns, with a major proportion of the mucin material with a density less than 1.44. These results therefore suggested that CF mucins had increased amounts of high density, and presumably more highly glycosylated, molecules.

This suggestion was confirmed by the analysis of carbohydrate as a function of mucin protein, as shown in Table 3. Total carbohydrate was significantly greater in the four CF specimens, compared with controls. Table 3 shows that this difference was entirely due to increased fucose, galactose, and $N$-acetylglucosa-

Table 1. Subjects from whom goblet cell mucin was isolated

\begin{tabular}{|c|c|c|c|c|}
\hline Age & Sex & Diagnosis & $\begin{array}{l}\text { Blood } \\
\text { group }\end{array}$ & Secretor status \\
\hline 38 & $\mathrm{M}$ & Renal failure & A & $\mathrm{A}, \mathrm{Le}^{\mathrm{b}+}$ \\
\hline 4 & $\mathbf{M}$ & Accident & A & $A, \mathrm{Le}^{\mathrm{b}+}$ \\
\hline 90 & $\mathrm{~F}$ & Cerebral vascular accident & & Non $\mathrm{H}, \mathrm{Le}^{\mathrm{a}+}$ \\
\hline 12 & $\mathbf{M}$ & Cirrhosis & $\mathrm{O}$ & Non $\mathrm{H}, \mathrm{Le}^{\mathrm{a}+}$ \\
\hline $1 / 365$ & $\mathrm{M}$ & Congenital lung cyst & A & Non $\mathrm{H}, \mathrm{Le}^{\mathrm{a+}}$ \\
\hline $5 / 12$ & $\mathrm{M}$ & Cerebral degeneration & $\mathrm{O}$ & $\mathrm{H}, \mathrm{Le}^{\mathrm{ht}}$ \\
\hline $9 / 12^{1}$ & $\mathrm{~F}$ & Blind loop syndrome & B & Not tested \\
\hline $34^{1}$ & $\mathrm{~F}$ & Mitral valve disease & A & $\mathrm{A}, \mathrm{Le}^{\mathrm{b}+}$ \\
\hline 23 & $\mathrm{~F}$ & $\mathrm{CF}$ & $\mathrm{AB}$ & Non $\mathrm{H}, \mathrm{Le}^{\mathrm{a}+}$ \\
\hline 9 & $\mathrm{~F}$ & $\mathrm{CF}$ & $\mathrm{O}$ & $\mathrm{H}, \mathrm{Le}^{\mathrm{b}+}$ \\
\hline 15 & $\mathrm{~F}$ & CF & $\mathrm{O}$ & $\mathrm{H}, \mathrm{Le}^{\mathrm{b+}}$ \\
\hline 23 & $\mathbf{M}$ & $\mathrm{CF}$ & $\mathrm{O}$ & Non $\mathrm{H}, \mathrm{Le}^{\mathrm{a}+}$ \\
\hline $19^{1}$ & $\mathrm{~F}$ & $\mathrm{CF}$ & $\mathrm{O}$ & $\mathrm{H}, \mathrm{Le}^{\mathrm{b+}}$ \\
\hline $18^{1}$ & $\mathrm{M}$ & $\mathrm{CF}$ & $\mathrm{o}$ & Not tested \\
\hline
\end{tabular}

' Subjects analysed at earlier period.

Table 2. Amino acid composition of control and cystic fibrosis small intestinal goblet cell mucin

\begin{tabular}{lrr}
\hline Amino Acid & Normal $(8)$ & \multicolumn{1}{c}{ CF (6) } \\
\hline Asp & $6.20 \pm 1.89^{1}$ & $6.02 \pm 0.71^{1}$ \\
Thr & $24.80 \pm 4.77$ & $23.37 \pm 2.68$ \\
Ser & $9.47 \pm 1.13$ & $10.25 \pm 1.49$ \\
Glu & $7.53 \pm 1.30$ & $6.88 \pm 2.03$ \\
Pro & $11.56 \pm 2.87$ & $11.03 \pm 1.39$ \\
Gly & $7.64 \pm 1.43$ & $6.81 \pm 0.71$ \\
Ala & $5.61 \pm 2.23$ & $5.10 \pm 0.35$ \\
1/2 Cys & Trace & Trace \\
Val & $4.67 \pm 1.13$ & $5.34 \pm 0.33$ \\
Met & $0.79 \pm 0.46$ & $0.74 \pm 0.46$ \\
Ilu & $3.23 \pm 0.75$ & $3.67 \pm 0.53$ \\
Leu & $5.13 \pm 1.38$ & $5.41 \pm 0.37$ \\
Tyr & $1.95 \pm 0.58$ & $2.43 \pm 0.94$ \\
Phe & $2.21 \pm 1.15$ & $2.95 \pm 1.00$ \\
His & $2.50 \pm 0.89$ & $2.30 \pm 0.93$ \\
Lys & $3.05 \pm 1.03$ & $3.24 \pm 0.67$ \\
Arg & $3.05 \pm 1.28$ & $2.86 \pm 0.99$ \\
\hline
\end{tabular}

${ }^{1}$ mole $/ 100$ mole (mean \pm S.D.) 
Table 3. Carbohydrate composition of small intestinal goblet cell mucin

\begin{tabular}{|c|c|c|}
\hline \multirow[b]{2}{*}{ nmole $/ \mu$ g protein } & Normal (6) & CF (4) \\
\hline & \multicolumn{2}{|c|}{ mean \pm S.D. } \\
\hline Total carbohydrate & $14.36 \pm 4.20$ & $22.87 \pm 3.41^{2}$ \\
\hline Fuc & $2.57 \pm 1.18$ & $5.94 \pm 2.30^{2}$ \\
\hline Gal & $4.32 \pm 1.93$ & $8.16 \pm 1.05^{2}$ \\
\hline GlcNAc & $2.54 \pm 1.32$ & $4.46 \pm 0.63^{1}$ \\
\hline GalNAc & $2.77 \pm 1.37$ & $2.64 \pm 0.77$ \\
\hline Sialic acid & $2.16 \pm 0.99$ & $1.68 \pm 0.36$ \\
\hline Mannose & $0.09 \pm 0.15$ & $0.02 \pm 0.01$ \\
\hline
\end{tabular}

${ }^{1} P<0.02$.

${ }^{2} P<0.01$.

mine because these three neutral monosaccharides were significantly increased in the CF mucins, whereas sialic acid and $\mathrm{N}$ acetylgalactosamine were unchanged. All mucins except one sample from the youngest subject contained less than 0.1 nmole mannose per $\mu \mathrm{g}$ protein, indicating that there was little non-mucin glycoprotein in the preparation.

When monosaccharides were expressed as mole \% of total carbohydrate (Table 4), the increase in the neutral monosaccharides fucose, galactose, and $\mathrm{N}$-acetylglucosamine was obscured because these sugars account for the majority of the total carbohydrate. The principal difference between $\mathrm{CF}$ and control mucins appeared as a significant reduction in mole \% sialic acid. The total of fucose, galactose, and $N$-acetylglucosamine was significantly increased, however. These results were not affected by inclusion of the four additional samples, although with 14 as opposed to 10 specimens, significant differences in mole $\% \mathrm{~N}$-acetylgalactosamine and fucose were also found.

Table 4 also demonstrates that there was little difference in the number of serine and threonine residues which were O-glycosidically linked to $N$-acetylgalactosamine (GalNAc/Thr + Ser molar ratio). This observation was not affected by excluding blood group A specimens from the calculations in order to avoid inclusion of chain terminal $\mathrm{N}$-acetylgalactosamine, and is consistent with a greater than $90 \%$ saturation of serine and threonine hydroxyls with oligosaccharide chains. The ratio of total moles carbohydrate to moles GalNAc was calculated in order to compare average chain length in the two groups. Although significance was not reached, even in 14 subjects, the mean chain length of CF mucins appeared to be approximately 2-3 moles longer than that of control mucin, with or without the A-positive mucins. Also, as one might expect, because fucose and sialic acid content vary in opposing directions, the fucose/sialic acid ratio was greatly increased in $\mathrm{CF}$ specimens.

Sedimentation coefficients were determined on 12 mucin sam- ples (Table 5) by band ultracentrifugation, a technique that sediments molecules of like shape according to molecular weight. In eight of these (four CF and four controls) two peaks, A and B, with rapid and slow sedimentation were resolved from which sedimentation coefficients $\left(\mathrm{S}^{\circ}{ }_{20, \mathrm{w}}\right)$ could be calculated. In one control and two CF samples only a single peak with the higher $\mathrm{S}^{\circ}{ }_{20, \mathrm{~W}}$ was visualized and in one control (age 1 day) calculation of $\mathrm{S}^{\circ}{ }_{20, \mathrm{w}}$ was only possible on the slower sedimenting peak, although a small rapidly sedimenting peak was seen. The mean $\mathrm{S}_{20, \mathrm{w}}$ of both species of the CF mucins was significantly greater than those of the control specimens. Table 5 also illustrates the total carbohydrate content per $\mu \mathrm{g}$ protein for each of the specimens where such data was available. There was a significant correlation between the carbohydrate content and the sedimentation coefficient of the heavier species, suggesting that it was this species of mucin molecule that predominantly accounts for the increase in carbohydrate content. Both ultracentrifugation and carbohydrate anal-

Table 5. Sedimentation coefficients of mucin samples $\left(S^{\circ}{ }_{20, W}\right)^{1}$

\begin{tabular}{lccc}
\hline \multicolumn{1}{c}{ Subject } & Species A & Species B & $\begin{array}{c}\text { Total carbohy- } \\
\text { drate (nmole/ } \\
\mu \text { g protein) }\end{array}$ \\
\hline $\begin{array}{l}\text { Control } \\
1\end{array}$ & 40.63 & 10.9 & 7.30 \\
2 & 57.43 & & 16.59 \\
3 & 54.93 & 10.34 & 12.66 \\
4 & 51.37 & 11.30 & 15.26 \\
5 & & 5.80 & 14.51 \\
6 & & & 19.82 \\
7 & 35.6 & 11.0 & \\
Mean \pm S.D. & $47.99 \pm 9.44$ & $9.89 \pm 2.26$ & $14.36 \pm 4.20$ \\
& & & \\
Cystic fibrosis & 59.24 & & 27.11 \\
8 & 61.48 & & 19.85 \\
9 & 65.19 & 10.97 & 24.11 \\
10 & 47.22 & 19.43 & 20.39 \\
11 & 51.5 & 14.7 & \\
12 & 59.0 & 15.15 & \\
13 & $57.27 \pm 6.66$ & $15.06 \pm 3.46$ & $22.87 \pm 3.41$ \\
Mean \pm S.D. & & & \\
& $P<0.05$ & $P<0.05$ & $P<0.01$ \\
\hline
\end{tabular}

\footnotetext{
${ }^{1}$ Correlation of $\mathrm{S}^{\circ}{ }_{20, \mathrm{w}}$ of Species A with total carbohydrate (nmole $/ \mathrm{mg}$ protein), $r=0.74, P<0.05$ (based on eight mucin specimens). No ultracentrifugation was performed in one control specimen due to the small sample size. In subject 6 no calculation could be performed because a discrete peak was not visualized (the majority of the material sedimented very slowly).
}

Table 4. Carbohydrate composition of small intestinal goblet cell mucin ${ }^{1}$

\begin{tabular}{lcccc}
\hline \multicolumn{1}{c}{$($ mole \%) } & Normal (8) & C.F. (6) & Normal (6) \\
\hline Fuc & $18.31 \pm 6.47$ & $24.78 \pm 5.29^{2}$ & $18.30 \pm 7.35$ & C.F. (4) \\
Gal & $30.29 \pm 7.05$ & $34.79 \pm 6.36$ & $29.22 \pm 7.27$ & $35.93 \pm 4.75$ \\
GlcNAc & $19.27 \pm 7.19$ & $21.92 \pm 4.14$ & $16.77 \pm 5.72$ & $19.55 \pm 1.76$ \\
GalNAc & $18.95 \pm 7.92$ & $12.12 \pm 5.03^{2}$ & $19.73 \pm 8.27$ & $11.62 \pm 3.62$ \\
Sialic acid & $13.35 \pm 8.46$ & $6.27 \pm 3.13^{2}$ & $16.19 \pm 7.84$ & $7.55 \pm 2.50^{2}$ \\
Mannose & $0.54 \pm 0.92$ & $0.12 \pm 0.05$ & $0.62 \pm 0.98$ & $0.10 \pm 0.0$ \\
Fuc + Gal + GlcNAc & $67.85 \pm 14.29$ & $85.55 \pm 6.30^{2}$ & $64.28 \pm 14.35$ & $80.82 \pm 4.50^{2}$ \\
GalNAc/Thr + Ser (mole/mole) & $1.06 \pm 0.44$ & $0.89 \pm 0.37$ & $0.95 \pm 0.27$ & $0.90 \pm 0.45$ \\
(A group deleted) & $0.97 \pm 0.35$ & $0.89 \pm 0.37$ & $0.92 \pm 0.34$ & $0.90 \pm 0.45$ \\
Average chain length & & & \\
(Total carbohydrate/GalNAc, mole/mole) & $6.44 \pm 3.41$ & $9.56 \pm 3.88$ & $6.24 \pm 3.61$ & $9.27 \pm 3.0$ \\
(A group deleted) & $7.18 \pm 4.26$ & $9.56 \pm 3.88$ & $6.53 \pm 4.62$ & \\
Fuc/sialic acid (mole/mole) & $2.02 \pm 1.34$ & $3.83 \pm 1.89^{2}$ & $1.57 \pm 1.24$ \\
\hline
\end{tabular}

'First two columns include four additional mucins not analysed per mg protein as in Table 3 . The third and fourth columns contain a comparison of the 10 mucins presented in Table 3.

${ }^{2} P<0.05$. 
ysis results agree in suggesting that there was an increase in larger, denser and more heavily glycosylated mucin species in cystic fibrosis.

The relationship between fucose and total carbohydrate per $\mu \mathrm{g}$ of protein was explored by linear regression analysis of all individual samples (Fig. 1a). Fucose and total carbohydrate were linearly and positively correlated $(r=0.86, \mathrm{P}<0.01)$. The four CF samples segregated towards the upper end of an apparently unbroken regressional line. In contrast, similar data comparing sialic acid per $\mu \mathrm{g}$ of protein and total carbohydrate per $\mu \mathrm{g}$ of protein showed no correlation and the amount of sialic acid changed insignificantly as the amount of carbohydrate increased from sample to sample (Fig. 1b). Thus the high fucose/sialic acid ratio was solely the result of the increase in fucose, which occurred as the chain length and glycosylation of the mucins increased. Figure 2 shows that the increase in fucose was not out of proportion to other neutral monosaccharides, however. Fucose (nmole/ $\mu \mathrm{g}$ protein) is plotted against galactose (nmole/ $\mu \mathrm{g}$ protein) for 10 of the mucin samples. The non-secretor samples are indicated by the asterisks. The dotted line is the regression line for all 10 samples and has a lower slope than the dashed line, which is the regression line for the five secretor samples. The solid line represents a slope of 1 . Thus, fucose increased at almost the same rate as galactose in the secretor samples (slope 0.89), whereas the rate of increase of fucose in the non-secretor samples was about half that of the secretor samples (slope 0.49 , not shown). The increase in fucose therefore was no greater than the rate of increase of galactose.

Sulfate was measured in eight samples (four CF, four controls) and the results are shown in Table 6 . The mean sulfate content

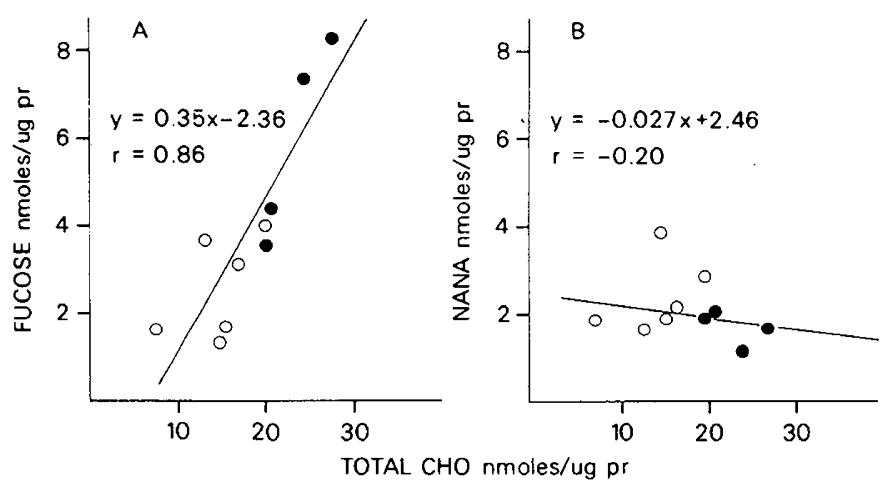

Fig. 1. Comparison of $(A)$ fucose and total carbohydrate, and $(B)$ NANA (sialic acid) and total carbohydrate per unit of mucin protein in six non-CF $\left(\mathrm{O}^{-} \mathrm{O}\right)$ and four $\mathrm{CF}(-\bullet)$ samples.

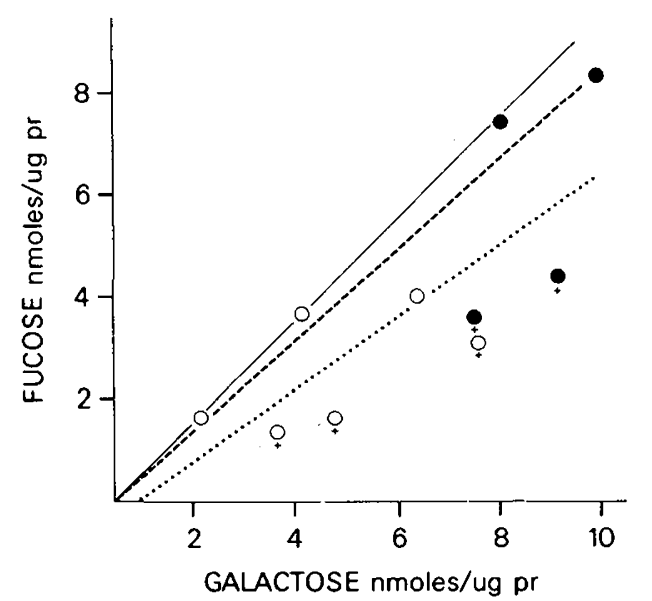

Fig. 2. Comparison of fucose with galactose content of mucins. (-), a theoretical line with a slope of 1 , indicating equal addition of fucose and galactose; (----) regression line for all points, $(y=0.73 x-0.37$, $\mathrm{r}=0.78)$; and $(----)$ regression line for secretors only, $(\mathrm{y}=0.89 \mathrm{x}+0.01$, $r=0.9)$. $(-\mathrm{CF}$; $(\mathrm{O}-\mathrm{O})$, non-CF; and $(+)$ nonsecretors.
Table 6. Sulfate content of small intestinal goblet cell mucin

\begin{tabular}{|c|c|c|}
\hline & Normal (4) & CF (4) \\
\hline & \multicolumn{2}{|c|}{ mean \pm S.D. } \\
\hline $\mathrm{SO}_{4} \mu$ mole $/ \mathrm{mg}$ protein & $0.863 \pm 0.377$ & $1.222 \pm 0.290$ \\
\hline $\begin{array}{l}\mathrm{Mole} \mathrm{SO}_{4} / \text { mole total } \\
\text { carbohydrate }\end{array}$ & $0.063 \pm 0.012$ & $0.054 \pm 0.015$ \\
\hline Mole $\mathrm{SO}_{4} /$ mole GlcNAc & $0.39 \pm 0.90$ & $0.28 \pm 0.07^{1}$ \\
\hline Mole $\mathrm{SO}_{4} / \mathrm{mole} \mathrm{Gal}$ & $0.22 \pm 0.05$ & $0.16 \pm 0.05$ \\
\hline $\begin{array}{l}\mathrm{Mole} \mathrm{SO}_{4} / \text { mole sialic } \\
\text { acid }\end{array}$ & $0.53 \pm 0.41$ & $0.77 \pm 0.25$ \\
\hline $\mathrm{Mole} \mathrm{SO}_{4} /$ mole GalNAc & $0.42 \pm 0.35$ & $0.47 \pm 0.05$ \\
\hline
\end{tabular}

${ }^{1} P<0.05$.

was higher in $\mathrm{CF}$ than control mucins, although this did not reach statistical significance. When the sulfate content was calculated per mole of total carbohydrate, or per mole of $N$-acetylglucosamine or galactose, the relative sulfation of the $C F$ mucin oligosaccharide was not increased since the sulfate $/ N$-acetylglucosamine ratio (mole/mole) was lower in the CF specimens. The content of sulfate (mole/mg protein) was positively correlated with total carbohydrate $(r=0.76, P<0.05)$ and also with $N$-acetylglucosamine $(r=0.84, P<0.01)$. This suggests that sulfate might be increased in CF specimens simply because of the increased oligosaccharide chain length, but the increase in sulfate does not appear to be fully proportional to the increase in galactose, $\mathrm{N}$ acetylglucosamine and fucose.

\section{DISCUSSION}

These results provide the first clear indication that purified human intestinal goblet cell mucin is qualitatively abnormal in cystic fibrosis. At the same time, they provide an explanation for the high fucose:sialic acid ratios noted by others in mucus glycoprotein fractions from meconium and duodenal secretions because it is evident that the fucose content of the intestinal mucins increased with galactose and $\mathrm{N}$-acetylglucosamine as part of a process of chain elongation and increased glycosylation. The chemical results were paralleled by ultracentrifugal evidence that fractions of high buoyant density with high sedimentation coefficients were more prominent in the $\mathrm{CF}$ mucins. Both of these parameters have been shown to correlate with the degree of glycosylation of mucins (3) and therefore provide independent confirmation of the abnormality.

Because three monosaccharides and probably sulfate are involved, it seems unlikely that the difference between $C F$ and nonCF mucins can be attributed to a specific glycosyl transferase step, unless it is one which in some way determines whether oligosaccharide chains elongate with neutral monosaccharides. Sialyl transferases may signal termination of oligosaccharides by adding sialic acid to the core $N$-acetylgalactosamine before addition to other sugars, but will fail to do so if preceded by the addition of galactose (2). Because there is no evidence from our data that sialylation is reduced, one would have to postulate that nonterminated chains are elongated in mucus-producing cells in cystic fibrosis. Alternatively, it is possible that the defect in cystic fibrosis reflects chain elongation in separate mucins which are independently programmed to have predominantly neutral or sulfated oligosaccharide chains. The large, dense mucin fraction which appears to be increased in cystic fibrosis has the ultracentrifugal characteristics of a neutral mucin fraction isolated by anion exchange chromatography (12). We have recently isolated sialic acid rich fractions which appear to correspond to the fractions with lower buoyant density (30). Gold, Shochat and Miller (14) have shown that proteolytically digested human colonic mucin contains two glycoproteins, which differ in amino acid, fucose and sialic acid content. One might speculate therefore that the cystic fibrosis defect encourages the production of one of these peptides preferentially, or in some manner stimulates its glycosylation.

Our evidence does not suggest that this defect is specific to 'cystic fibrosis in that there was some overlapping of results with 
the control samples. Unfortunately, heterozygote samples could. not be identified. Chain elongation could be controlled by other processes such as the rate of synthesis and secretion which may be coupled more indirectly to the gene defect. Abnormalities of $\mathrm{Cl}^{-}$, $\mathrm{HCO}_{3}{ }^{-}$and water secretion are well recognized in cystic fibrosis (13) and each might affect the release of goblet cell mucus in a critical manner.

It is too early to decide whether elongation of oligosaccharide chains and hyperglycosylation could influence the pathology of cystic fibrosis. The dominant feature which controls the gelation of mucins appears to be their polymeric structure maintained by a disulfide-linked peptide (1). The role of carbohydrate in determining the point and degree of gelatin is less clear, chiefly because a homologous series of native mucins differing only in chain length has never been isolated or studied. Size and glycosylation are related to hydrodynamic radius, however, and it is likely that the longer the oligosaccharide chains and the larger the mucin, the earlier molecular interactions will occur between :mucin molecules. Thus, it is possible that the defect described in this paper might cause $C F$ mucins to gel at a lower concentration. The tendency to higher sulfate and lower sialic acid content may also affect the interaction between mucus and metal ions (11) and viruses (8).

Finally, it is important to consider whether our results could be influenced by pancreatic insufficiency and antibiotic therapy. Pancreatic insufficiency was present in all the CF subjects in this study. It has not yet been possible to examine the small intestinal mucus of a nonCF subject with pancreatic insufficiency. Mucins have been shown to be susceptible to proteolytic digestion of their nonglycosylated portions (33). Thus, the absence of pancreatic proteases might be expected to lead to a mucin with a higher proportion of protein and a relatively lower content of carbohydrate, and would not account for the highly glycosylated $\mathrm{CF}$ mucus.

Roy et al. (32) have shown that children with CF receiving i.v. therapy with Cloxacillin, Gentamycin and Carbenicillin had a marked reduction in faecal anaerobic flora compared with normal controls, CF children off antibiotics, and CF children on oral Cloxacillin. Degradation of mucins by anaerobic bacteria of faeces has been shown by Hoskins and Zamcheck (16), but in humans, the major site of mucus carbohydrate degradation appears to be the distal ileum and colon (35), rather than the small intestine where bacterial counts are lower (26). The small intestinal tissue used in this study was washed free of luminal contents, so that the majority of the mucus glycoprotein was intracellular, or derived from deeper portions of intestinal crypts where bacterial degradation would be minimal. It seems unlikely, therefore, that variable mucin degradation due to antibiotics could have influenced results. Bacterial glycosidases would, in any case, be unlikely to cleave fucose, galactose and $N$-acetylglucosamine selectively, while sparing blood group determinants and sialic acid.

As a minimum, these results suggest that further research on the relationship between the viscosity of mucins and the extent of their glycosylation may help us to understand the role of mucins in the pathogenesis of cystic fibrosis.

\section{REFERENCES AND NOTES}

1. Allen, A.: Structure of gastrointestinal mucus glycoproteins and the viscous and gel-forming properties of mucus. Brit. Med. Bull., 34: 28 (1978).

2. Beyer, T. A., Rearick, J. I., Paulson, J. C., Prieels. J. P., Sadler, J. E., and Hill, R. L.: Biosynthesis of mammalian glycoprotein. J. Biol. Chem., 254: 12531 (1979).

3. Bhaskar, K. R. and Creeth, J. M.: The macromolecular properties of bloodgroup-specific glycoproteins. Biochem. J., 143: 669 (1974).

4. Boat, T. F., Cheng, P. W., Iger, R. M., Carlson, D. M., and Polony, I.: Human respiratory tract secretions. Mucous glycoproteins of non-purulent tracheobronchial secretions, and sputum of patients with bronchitis and cystic fibrosis. Arch. Biochem. Biophys., 177: 95 (1976)

5. Chervenka, C. H.: A manual of methods for the analytical ultracentrifuge. Spinco Div., Beckman Instruments, Palo Alto, California.

6. Clamp, J. R., Bhatti, T., and Chambers, R. E.: The determination of carbohydrate in biological materials by gas-liquid chromatography. Methods Biochem. Anal.,
19: $229^{-}(1971)$

7. Clamp, J. R. and Gough, M.: Study of the oligosaccharide units from mucus glycoproteins of meconium from normal infants and from cases of cystic fibrosis with meconium ileus. Clin. Sci., 57: 445 (1979).

8. DiGirolamo, R., Liston, J., and Matches, J.: Ionic binding: the mechanism of viral uptake by shellfish mucus. Appl. Environ. Microbiol., 33: 19 (1977).

9. Dische, Z., di Sant 'Agnese, P., Pallavicini, C., and Youlos, J.: Composition of mucoprotein fractions from duodenal fluid of patients with cystic fibrosis of the pancreas and from controls. Pediatrics, 24: 74 (1959).

10. Farber, S.: Some organic digestive disturbances in early life. J. Michigan Med. Soc., 44: 587 (1945).

11. Forstner, J. and Forstner, G: Calcium binding to intestinal goblet cell mucin Biochim. Biophys. Acta, 386: 283 (1975).

12. Forstner, J. F., Jabbal, I., Qureshi, R., Kells, D. I. C., and Forstner, G. G.: The role of disulphide bonds in human intestinal mucin. Biochem. J., 181: 725 (1979)

13. Gaskin, K. J., Durie, P. R., Corey, M., Wei, P., and Forstner, G. G.: Evidence for a primary defect of pancreatic $\mathrm{HCO}_{3}^{-}$secretion in cystic fibrosis. Pediatr. Res. 16: 554 (1982).

14. Gold, D. V., Shochat, D., and Miller, F.: Protease digestion of colonic mucin Evidence for the existence of two immunochemically distinct mucins. J. Biol. Chem., 256: 6354 (1981).

15. Guha, A. K., Kutty, K. M., Chandra, R. K., and Way, R. C.: A study of the salivary glycoprotein in cystic fibrosis patients and controls: fucose incorporation and protein pattern. Clin. Biochem., 10: 153 (1977)

16. Hoskins, L. C. and Zamcheck, N.: Bacterial degradation of gastrointestinal mucin. 1. Comparison of mucin constituents in the stools of germ-free and conventional rats. Gastroenterology, 54: 210 (1968).

17. Jabbal, I., Forstner, G., Forstner, J., and Kells, D. I. C.: Sedimentation velocity studies on microgram quantities of rat intestinal goblet cell mucin. Analyt. Biochem., 69: 558 (1975)

18. Jabbal, I., Kells, D. I. C., Forstner, G., and Forstner, J.: Human intestinal goblet cell mucin. Canad. J. Biochem., 54: 707 (1976).

19. Johansen, P. G.: Some observations on mucous secretions in cystic fibrosis of pancreas. Ann. New York Acad. Sci., 106: 755 (1963).

20. Lamb, D. and Reid, L.: Acid glycoproteins produced by the mucous cells of the bronchial submucosal glands in the fetus and child. A histochemical autoradiographic study. Brit. J. Dis. Chest, 66: 248 (1972).

21. Lamb, D. and Reid, L.: The tracheobronchial submucosal glands in cystic fibrosis: A qualitative and quantitative histochemical study. Brit. J. Dis. Chest, 66: 239 (1972).

22. Lamblin, G., Lafitte, J. J., L'Hermitte, M., Degand, P., and Roussel, P.: Mucins from cystic fibrosis sputum. Mod. Probl. Pediatr., 19: 153 (1977),

23. Layne, E.: Protein estimation by ultraviolet absorption. In: S. P. Colwick and N O. Kaplan, Eds.: Methods in Enzymology, Vol. III. pp. 451-454. (Academic Press, New York, 1957).

24. Lev, R. and Spicer, S. S.: A Histochemical comparison of human epithelial mucin in normal and in hypersecretory states including pancreatic cystic fibrosis. Am. J. Pathol., 46: 23 (1965).

25. Mende, T. J. and Whitney, P. L.: Microdetermination of inorganic sulfate using thin layer plates. Analyt. Biochem., 84: 570 (1978).

26. Moore, W. E. C., Cato, E. P., and Hredeman, L. V.: Anaerobic bacteria of the gastrointestinal flora and their occurrence in clinical infections. J. Infect. Dis., 119: 641 (1969).

27. Morrissey, S. M. and Tymvios, M. C.: Acid mucin in human intestinal goblet cells. J. Path., 126: 197 (1978)

28. Oakley, B. R., Kirsch, D. R., and Morris, N. R.: A simplified ultrasensitive silver stain for detecting proteins in polyacrylamide gels. Analyt. Biochem., 105: 361 (1980).

29. Potter, J. L., Matthews L.. W., Lemm, J., and Spector, S.: Human pulmonary secretion in health and disease. Ann. New York Acad. Sci., 106: 692 (1963).

30. Qureshi, R., Wesley, A., Forstner, G., and Forstner, J.: Properties of human intestinal mucin. In: J. M. Sturgess, Ed.: Perspectives in Cystic Fibrosis. Proceedings of the 8th International Congress on Cystic Fibrosis. p. 30a (Imperial Press Ltd., Mississauga, Ont. 1980).

31. Roelfs, R. E., Gibbs, G. E., and Griffin, G. D.: Composition of rectal mucus in cystic fibrosis. Am. J. Dis. Child., 113: 419 (1967).

32. Roy, C. C., Delage, G., Fontaine, A., Robitaille, L., Chartrand, L., Weber, A., and Morin, C. L.: The fecal microflora and bile acids in children with cystic fibrosis. Am. J. Clin. Nutr., 32: 2404 (1979).

33. Scawen, M. and Allen, A.: The action of proteolytic enzymes in the glycoproteins from pig gastric mucus. Biochem. J., 163: 363 (1977)

34. Spiro, R. G.: Analysis of sugars found in glycoproteins. In: E. F. Neufeld and V. Ginsberg, Eds.: Methods in Enzymology, Vol. VIII, pp. 3-26. (Academic Press, New York, 1966).

35. Vercellotti, J. R., Salyers, A. A., Bullard, W. S., and Wilkins, T. D.: Breakdown of mucin and plant polysaccharides in the human colon. Can. J. Biochem., 55: 1190 (1977).

36. Zanetta, J. P., Brenkenridge, W. C., and Vincendon, G.: Analysis of monosaccharides by gas-liquid chromatography of the O-methyl glycosides as trifluoroacetate derivatives. J. Chromatogr., 69: 291 (1972).

37. Requests for reprints should be addressed to: Dr. Gordon Forstner, Research Institute, Hospital for Sick Children, 555 University Avenue, Toronto, Ontario M5G 1X8, Canada.

38. Received for publication January 8,1982

39. Accepted for publication April 23, 1982. 